\title{
Optimization of the Extraction of the Volatile Fraction from Honey Samples by SPME-GC-MS, Experimental Design, and Multivariate Target Functions
}

\author{
Elisa Robotti, ${ }^{1}$ Federica Campo, ${ }^{1}$ Marta Riviello, ${ }^{1}$ Marco Bobba, ${ }^{1,2}$ \\ Marcello Manfredi, ${ }^{1}$ Eleonora Mazzucco, ${ }^{1}$ Fabio Gosetti, ${ }^{1}$ Giorgio Calabrese, ${ }^{3}$ \\ Emanuele Sangiorgi, ${ }^{2}$ and Emilio Marengo ${ }^{1}$ \\ ${ }^{1}$ Department of Sciences and Technological Innovation, University of Piemonte Orientale, Viale Michel 11, 15121 Alessandria, Italy \\ ${ }^{2}$ Istituto Zooprofilattico Sperimentale della Lombardia e dell'Emilia Romagna, Via Bianchi 9, 25124 Brescia, Italy \\ ${ }^{3}$ Department of Pharmacy, Università degli Studi di Napoli Federico II, Via Montesano 49, 80131 Napoli, Italy
}

Correspondence should be addressed to Elisa Robotti; elisa.robotti@uniupo.it

Received 5 September 2016; Revised 17 December 2016; Accepted 4 January 2017; Published 9 February 2017

Academic Editor: Shayessteh Dadfarnia

Copyright (C) 2017 Elisa Robotti et al. This is an open access article distributed under the Creative Commons Attribution License, which permits unrestricted use, distribution, and reproduction in any medium, provided the original work is properly cited.

\begin{abstract}
Head space (HS) solid phase microextraction (SPME) followed by gas chromatography with mass spectrometry detection (GC-MS) is the most widespread technique to study the volatile profile of honey samples. In this paper, the experimental SPME conditions were optimized by a multivariate strategy. Both sensitivity and repeatability were optimized by experimental design techniques considering three factors: extraction temperature (from $50^{\circ} \mathrm{C}$ to $70^{\circ} \mathrm{C}$ ), time of exposition of the fiber (from $20 \mathrm{~min}$ to $60 \mathrm{~min}$ ), and amount of salt added (from 0 to 27.50\%). Each experiment was evaluated by Principal Component Analysis (PCA) that allows to take into consideration all the analytes at the same time, preserving the information about their different characteristics. Optimal extraction conditions were identified independently for signal intensity (extraction temperature: $70^{\circ} \mathrm{C}$; extraction time: $60 \mathrm{~min}$; salt percentage: $27.50 \% \mathrm{w} / \mathrm{w}$ ) and repeatability (extraction temperature: $50^{\circ} \mathrm{C}$; extraction time: $60 \mathrm{~min}$; salt percentage: $27.50 \% \mathrm{w} / \mathrm{w}$ ) and a final global compromise (extraction temperature: $70^{\circ} \mathrm{C}$; extraction time: $60 \mathrm{~min}$; salt percentage: $27.50 \% \mathrm{w} / \mathrm{w}$ ) was also reached. Considerations about the choice of the best internal standards were also drawn. The whole optimized procedure was than applied to the analysis of a multiflower honey sample and more than 100 compounds were identified.
\end{abstract}

\section{Introduction}

Honey is gaining increasing commercial importance due to not only its nutritional properties but also its therapeutic and healing effects [1-3]. In the last years, increasing attention has been devoted to the characterization of the profile of volatile molecules in honey samples above all in authenticity and adulteration studies [4-22], since the commercial value of honey is usually strictly correlated to its botanical and/or geographical origin. Unifloral honeys are certainly more valuable than multifloral; products show a different commercial value based on their botanical origin, particularly when the origin is strictly defined, for example, for PDO (Protected Designation of Origin) products.
The volatile profile is usually determined by HeadSpace Solid Phase Micro-Extraction (HS-SPME), followed by a gas chromatographic (GC) determination with Mass Spectrometry (MS) detection [4-19]. HS-SPME GC-MS is quite widespread both as a fingerprinting tool [23-26] and for identification and quantification of specific classes of compounds or single analytes [27]: it is applied to honey samples in food safety and adulteration studies (for the determination of residues of chemicals used to combat honeybee diseases or parasite infestations, as fungicides, insecticides, acaricides, and pesticides [28]) or in authenticity studies for the determination of botanical biomarkers [29-31].

In HS-SPME particular attention has to be paid to the optimization of the extraction procedure that is subjected 
to the effect of several experimental parameters as conditioning time, extraction time and temperature, ionic strength, amount of sample, water/sample ratio, sample solution/ headspace volume ratio, and type of fiber used for SPME. The optimization step allows the selection of the best experimental conditions to be applied during the extraction to provide the best extraction yield avoiding in the meantime fiber saturation.

In SPME, optimization is usually accomplished by a monovariate approach in which one parameter is optimized at a time [32]. In this way, no evaluation of the interactions existing between the parameters can be accomplished. Experimental design techniques have also been applied [33-43] but few applications are present regarding honey [44-46].

One of the drawbacks of SPME is its low repeatability, if compared to other extraction techniques: to improve repeatability, the achievement of the equilibrium during the adsorption of the analytes on the fiber is mandatory. Notwithstanding the use of experimental design to improve repeatability is reported in literature [47] for other applications, optimization in SPME is usually carried out to maximize signal intensity alone, that is, gas-chromatographic peak areas.

Moreover, most of applications of SPME to honey report optimized conditions identified using two main strategies:

(1) when the monovariate approach is adopted, optimization is usually accomplished on a set of selected analytes, representative of the analytes present $[30,33$, 35-38];

(2) both in monovariate optimization and when experimental design tools are exploited, global signal is defined for each experiment as the average or the sum of the areas of all the peaks identified in the chromatogram $[34,35,39-46]$. This approach takes into account the presence of several analytes but no information is retained about the different physicalchemical characteristics of each species.

A true multivariate target function could be defined by the use of desirability or utility functions $[48,49]$ or by using Principal Component Analysis (PCA) [49-51]. A multivariate procedure has been previously proposed by our research group for the optimization of the instrumental parameters in MS determinations and for the elemental profiling in Inductively Coupled Plasma Mass Spectrometry (ICP-MS) [51]. A similar procedure has been recently applied by Ribeiro et al. to the extraction of the volatiles from coffee and compared to desirability functions [49].

To overcome the above mentioned limitations, optimization of both signal intensity (expressed as chromatographic peak areas) and repeatability (expressed as the coefficient of variation, $\mathrm{CV} \%$, of each peak area across replications of the same experiment) was carried out here by experimental design. Three main factors underwent optimization: temperature and time of extraction and the ionic strength, expressed as amount of salt added to the sample. PCA was used as a dimensionality reduction tool, to provide a multivariate target function for the optimization phase so that all the analytes are taken into account, each one described by its own area (for signal intensity optimization) or coefficient of variation (for repeatability optimization). Optimal extraction conditions were identified for both signal intensity and repeatability separately, and a final global optimal compromise was also reached. Some considerations on the choice of the most suitable internal standard were also drawn. The main novelty here proposed is coupling experimental design with the establishment of a multivariate target function for the optimization of both signal intensity and repeatability; to the authors' knowledge the optimization of both these parameters is reported here for the first time to the SPME procedure for honey samples.

\section{Theory}

2.1. Experimental Design. Experimental design techniques allow the evaluation of the effect played by a set of experimental factors on a selected experimental response by the use of the most informative and most exiguous set of experiments [52]. Here, experimental design was exploited for the optimization of the SPME procedure [39-42] according to both the maximum signal intensity and repeatability.

A two-level full factorial design was chosen for studying the effect played by three factors: extraction temperature ( $T$, in ${ }^{\circ} \mathrm{C}$ ), extraction time ( $t$, in $\mathrm{min}$ ), and amount of salt (salt, expressed as $\% \mathrm{w} / \mathrm{w}$ ). The experimental design requires a total of $2^{p}$ ( $p=$ number of factors) experiments, that is, $2^{3}=8$ experiments. The center of the experimental domain was added to evaluate the potential curvature of the system behavior. The experimental domain explored for each factor is defined in Table 1, together with the experiments carried out.

The adopted design allows the evaluation of the effect of all principal factors and their two- and three-order interactions, that is, of the general Ordinary Least Squares (OLS) model:

$$
\begin{aligned}
y= & b_{0}+b_{1} \cdot T+b_{2} \cdot t+b_{3} \cdot \text { salt }+b_{4} \cdot T \cdot t+b_{5} \cdot T \cdot \text { salt } \\
& +b_{6} \cdot t \cdot \text { salt }+b_{7} \cdot T \cdot t \cdot \text { salt }
\end{aligned}
$$

where the coefficients $b_{i}$ estimate the effect of the corresponding variable or interaction on the response $y$. The complete experimental design, including the center of the domain, was replicated three times (a total of 27 experiments) to provide information about the experimental repeatability.

Here the experimental response $y$ was defined by a multivariate target function, based on PCA.

Each experiment was described by the chromatographic profile obtained, consisting of a total of 143 peak areas. The optimization of signal intensity (peak area) is usually accomplished in literature by submitting to optimization the average [44] or the sum [34, 35, 39, 45, 46] of the areas calculated for all the identified peaks. This choice does not take into account the correlation structure of the data. The analytes belong to different chemical classes characterized by different physical-chemical properties and, in particular, different volatility: so the average or the sum does not allow considering the existence of groups of analytes with similar or opposite behavior. The same considerations can be driven about repeatability that is usually described for each $i$ th 
TABLE 1: Experimental domain investigated: low (-), intermediate $(0)$, and high (+) levels adopted for each experimental factor.

\begin{tabular}{|c|c|c|c|}
\hline & $\begin{array}{l}\text { Extr. temperature } \\
(T)\end{array}$ & $\begin{array}{l}\text { Extr. time } \\
\quad(t)\end{array}$ & $\begin{array}{c}\text { Amount of salt } \\
\text { (salt) }\end{array}$ \\
\hline Exp 1 & - & - & - \\
\hline Exp 2 & + & - & - \\
\hline Exp 3 & - & + & - \\
\hline Exp 4 & + & + & - \\
\hline Exp 5 & - & - & + \\
\hline Exp 6 & + & - & + \\
\hline Exp 7 & - & + & + \\
\hline Exp 8 & + & + & + \\
\hline \multirow[t]{3}{*}{ Exp 9} & 0 & 0 & 0 \\
\hline & \multicolumn{3}{|c|}{ Experimental domain } \\
\hline & $T\left({ }^{\circ} \mathrm{C}\right)$ & $t(\min )$ & $\begin{array}{c}\text { Salt (\% w/w } \\
\text { honey) }\end{array}$ \\
\hline- & 50 & 20 & 0 \\
\hline+ & 70 & 60 & 27.50 \\
\hline $\mathbf{0}$ & 60 & 40 & 13.75 \\
\hline
\end{tabular}

experiment and each $j$ th peak as the coefficient of variation (CV) of the area of the jth peak calculated across three or more replications of the same $i$ th experiment:

$$
\mathrm{CV}_{i, j} \%=\frac{s_{i, j}}{\bar{x}_{i, j}} * 100 \text {, }
$$

where $s_{i, j}$ is the standard deviation of the $j$ th peak of the $i$ th experiment and $\bar{x}_{i, j}$ is the average area of the $j$ th peak of the $i$ th experiment. Again, the description of each experiment by the use of the average CV\% or the sum of all CV\% is not an effective choice.

2.2. Principal Component Analysis (PCA). A true multivariate target function was defined here by means of PCA [53]. As commonly acknowledged, PCA represents the objects in a new reference system characterized by new variables called Principal Components (PCs), orthogonal one to each other and computed hierarchically, that is, in decreasing order of explained variance. The PCs therefore account for independent sources of information, relegating experimental noise and random variations in the last PCs. PCA can be exploited to provide a multivariate target function for signal intensity and repeatability optimization.

(i) Signal Intensity. PCA was carried out on the dataset consisting of all the experiments performed $(9 \times 3=27$ experiments), each described by the areas of the 143 peaks. In this case, a target function can be identified if a meaningful direction of optimization can be defined in the space given by the relevant PCs. For this purpose two simulated experiments were defined, representing the "best" and the "worst" experiments for what regards signal intensity. They were calculated from the results of the experimental design as follows:

$$
\begin{aligned}
\text { best }_{j} & =\max (x)_{j}+20 * \frac{\max (x)_{j}}{100}, \\
\text { worst }_{j} & =\min (x)_{j}-20 * \frac{\min (x)_{j}}{100},
\end{aligned}
$$

where $j$ identifies the $j$ th peak; the minimum and maximum values are calculated over the areas of the $j$ th peak among all the experiments of the design. In this way, the best experiment is defined as the one characterized by the largest areas recorded along the design experiments plus 20\% (best signal intensity) and the worst is defined as the one characterized by the smallest areas minus 20\% (worst signal intensity). These two experiments can be reprojected in the space given by the relevant PCs to identify the direction of optimization as the direction connecting them. All experiments can be therefore projected onto the optimization direction and described in terms of their distance from the best experiment along this direction; the distance thus defined can be used as a multivariate target function: the smallest the distance from the best experiment, the largest the signal intensity.

(ii) Repeatability. PCA was carried out on the dataset consisting of the 9 experiments of the design, each described by the $\mathrm{CV} \%$ of each peak area. In this case, the $\mathrm{CV} \%$ was calculated for each peak and each experiment from the three replications of the design. Also in this case a target function can be identified if a direction of optimization can be defined in the space of the relevant PCs. Again, the "best" and the "worst" experiments for what regards repeatability can be calculated and reprojected in the space of the relevant PCs:

$$
\begin{aligned}
\text { best }_{j} & =\min (\mathrm{CV})_{j}-20 * \frac{\min (\mathrm{CV})_{j}}{100}, \\
\text { worst }_{j} & =\max (\mathrm{CV})_{j}+20 * \frac{\max (\mathrm{CV})_{j}}{100},
\end{aligned}
$$

where $j$ indicates the $j$ th peak; the minimum and maximum values are calculated over the $\mathrm{CV} \%$ of the $j$ th peak calculated for all the experiments of the design. The best experiment is therefore defined as the one characterized by the smallest CV\% recorded over the design experiments minus 20\% (best repeatability) and the worst as the one characterized by the largest CV\% plus 20\% (worst repeatability). Again, the distance of each experiment from the best along the optimization direction thus defined can be used as a multivariate target function: the smallest this distance, the best the repeatability.

2.3. Calculation of Regression Models. Regression models were then built relating the distance of each experiment from "best" along the optimization functions established for signal intensity and repeatability, to the investigated factors and their interactions. Only statistically relevant ( $p$-level $<0.05$ ) coefficients of experimental factors and/or factors interactions were included in the final models and were identified by ANOVA (ANalysis Of VAriance) [52]. Thanks to the availability of replicated experiments, the model for signal 
intensity could be tested for curvature effects by ANOVA [52].

\section{Materials and Methods}

3.1. SPME Conditions. SPME was carried out in $20 \mathrm{~mL}$ Glass Headspace Vials $(22.5 \times 75 \mathrm{~mm}$; Supelco, Bellefonte, PA, USA) with aluminum seals equipped with PTFE/silicone septa (Supelco, Bellefonte, PA, USA). SPME was carried out with a 50/30 $\mu \mathrm{m}$ DVB/CAR/PDMS fiber (Stableflex, Supelco, Bellefonte, PA, USA). Extraction was carried out on $4 \mathrm{~g}$ of honey, added with $5.5 \mathrm{~mL}$ milliQ water and internal standards $(42.5 \mu \mathrm{L}$ o-tolualdehyde $10.0 \mathrm{mg} / \mathrm{L}, 42.5 \mu \mathrm{L} 2,4,6$ trimethylphenol $10.0 \mathrm{mg} / \mathrm{L}, 85 \mu \mathrm{L}$ benzophenone $10.0 \mathrm{mg} / \mathrm{L}$ ). The volume ratio honey/water adopted was chosen to avoid saturation effects on the fiber and achieve a ratio solution : headspace of about $1: 1$, to guarantee the establishment of the equilibrium [54].

When prescribed by the experimental design, salt was added to the samples as aqueous solution at $100 \mathrm{~g} / \mathrm{L}$ and $200 \mathrm{~g} / \mathrm{L}$. The addition to the sample of $5.5 \mathrm{~mL}$ of the first or second solution provides a final concentration of salt of 13.75 or $27.50 \%$ expressed as weight of salt over weight of honey (Table 1). Saturated salt solutions were avoided to improve repeatability: the use of saturated solutions causes in general a low repeatability probably due to adsorption effects at the surface of crystals that can be present in the solution.

All experiments were performed on the same commercial organic multiflower honey and preliminary results demonstrated that no degradation took place at the extraction temperature adopted in the study: comparing the experiments carried out while increasing the extraction temperature, all peaks areas increased and no new peak appeared at high temperature.

3.2. GC-MS Analyses. GC-MS analyses were performed by a GC system Saturn CP-3800 (Varian, Walnut Creek, CA, USA) equipped with an ion trap mass analyzer Saturn 2200 (Varian, Walnut Creek, CA, USA); ionization was accomplished by EI at $70 \mathrm{eV}$ and $\mathrm{MS}$ acquisition was carried out in full scan mode in the range $35-400 \mathrm{~m} / z$. GC separations were performed on a capillary column VF-5MS $(30 \mathrm{~m} \times 0.25 \mathrm{~mm} \times 0.25 \mu \mathrm{m}$, Varian, Walnut Creek, CA, USA) and helium was used as carrier gas with a constant flow rate of $1.00 \mathrm{~mL} / \mathrm{min}$. The $\mathrm{GC}$ temperature program was as follows: from 35 to $70^{\circ} \mathrm{C}$ at $5^{\circ} \mathrm{C} / \mathrm{min}, 70^{\circ} \mathrm{C}$ for $15 \mathrm{~min}$, from 70 to $100^{\circ} \mathrm{C}$ at $5^{\circ} \mathrm{C} / \mathrm{min}$, $100^{\circ} \mathrm{C}$ for $15 \mathrm{~min}$, from 100 to $250^{\circ} \mathrm{C}$ at $7^{\circ} \mathrm{C} / \mathrm{min}, 250^{\circ} \mathrm{C}$ for $2 \mathrm{~min}$. The injector temperature was set at $230^{\circ} \mathrm{C}$ in splitless mode for the first $5 \mathrm{~min}$ and then with a split ratio $1: 100$. Three internal standards (IS) were used: o-tolualdehyde, 2,4,6-trimethylphenol, and benzophenone (Sigma Aldrich, Milwaukee, WI, USA).

3.3. Data Analysis. PCA, regression models, calculations, and graphical representations were performed by The Unscrambler X 10.2 (Camo, Oslo, Norway), Statistica v.7.1 (StatSoft Inc, Tulsa, OK, USA), Matlab R2014b (The Mathworks, Natick, MA, USA), and Excel 2007 (Microsoft Corporation, Redmond, WA, USA).

\section{Results and Discussion}

4.1. Evaluation of the Amount of Sample. As commonly acknowledged, in SPME, the amount of sample used during extraction is a key point to provide the highest signal intensity while avoiding saturation effects occurring on the fiber. Starting from the most of applications present in literature, reporting amounts of sample ranging from about 2 to over $16 \mathrm{~g}$ of honey, we decided to investigate different amounts by keeping the sample solution : headspace volume ratio almost constant at about 1 [54]. Three experiments were therefore carried out in the same experimental conditions for what concerns both SPME and GC-MS, using 2.00, 4.00, and $8.00 \mathrm{~g}$ honey added with 7.0, 5.5, and $3.0 \mathrm{~mL}$ water, respectively. Each experiment was therefore described by the area of the 143 peaks recorded in the chromatogram. Figure 1 reports the results obtained: the peaks are reported on $x$-axis in order of elution, while the corresponding areas are reported on the $y$ axis (the darker the marker, the highest the sample amount). For most of the peaks the areas increase in the order 2-4-8g of honey, showing that for these peaks no saturation effect is present. For other peaks two different behaviors occur: (1) an increase between 2 and $4 \mathrm{~g}$ but not between 4 and $8 \mathrm{~g}$ (saturation effects are present with $8 \mathrm{~g}$ ); (2) an increase between 4 and $8 \mathrm{~g}$ but not between 2 and $4 \mathrm{~g}$ (low signal intensity in the range $2-4 \mathrm{~g}$ ). From these considerations we decided to use $4 \mathrm{~g}$ of honey in the successive experiments.

The experiments of the replicated experimental design were performed in a randomized order.

4.2. Optimization of Signal Intensity. PCA was carried out on the $(27 \times 143)$ data matrix, 27 being the number of replicated experiments of the experimental design and 143 being the areas of the identified peaks. The data matrix was autoscaled before PCA. The first 2 PCs were considered significant (accounting for about $66 \%$ of the overall variance: $\mathrm{PC}_{1}=$ $\left.46.99 \%, \mathrm{PC}_{2}=18.93 \%\right)$.

Figures 2(a) and 2(b) report the loading plots of the first two PCs: loadings are reported separately for each PC; the $x$ axis reports the peaks in order of elution from left to right while the $y$-axis reports the corresponding loadings. As it can be observed from the figures, the first PC is mainly related to the behavior of the peaks eluting in the second part of the chromatogram (long retention times), almost all characterized by large positive loadings; an opposite behavior is observed for $\mathrm{PC}_{2}$, which shows large negative loadings of the peaks belonging to the first part of the chromatogram (short retention times). The first two PCs are therefore able to sum up the information about peak areas depending on retention time, that is, about signal intensity: experiments with large signal intensity (large peak areas) are characterized by large positive scores on $\mathrm{PC}_{1}$ and large negative ones on $\mathrm{PC}_{2}$. The information about signal intensity is therefore separated in the first two components, each one related to different retention times of the analytes.

Figure 2(c) reports the corresponding score plot but labels the scores according to temperature. The score plot reports also the two simulated experiments described in the theory section, labeled, respectively, "best" and "worst," indicating 


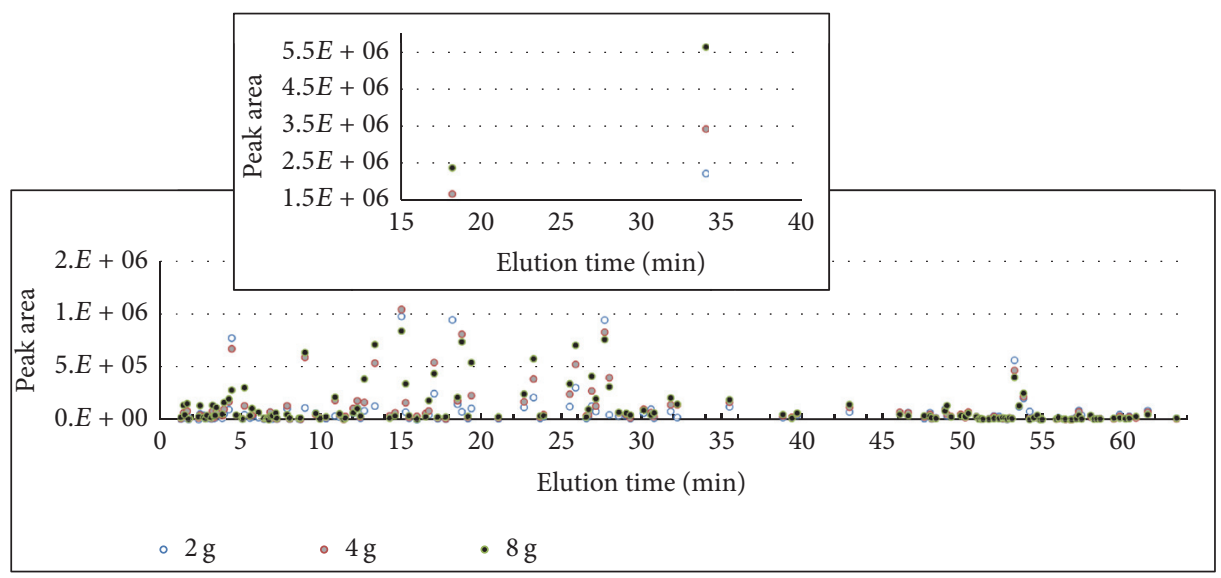

FIGURE 1: Evaluation of the optimal amount of sample in SPME GC-MS analysis: areas ( $y$-axis) of each peak identified by its elution time ( $x$-axis) using the experimental conditions reported in Section 4.1. Circles are represented on a color scale: the darker the circle, the larger the amount of honey. An enlargement is provided for the region of elution time between 15 and 40 minutes due to scale effects.

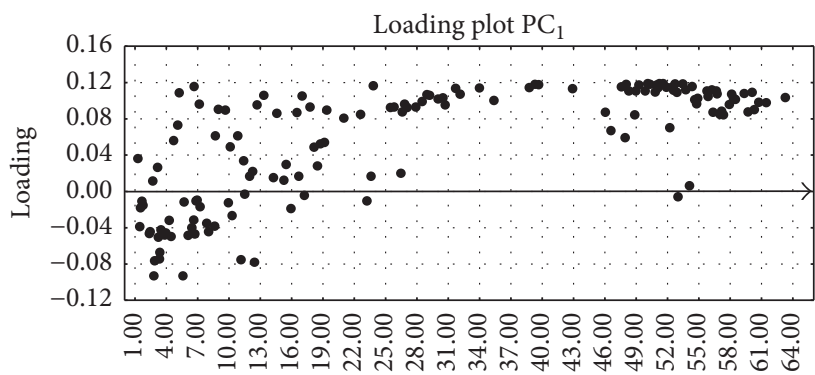

Elution time

(a)

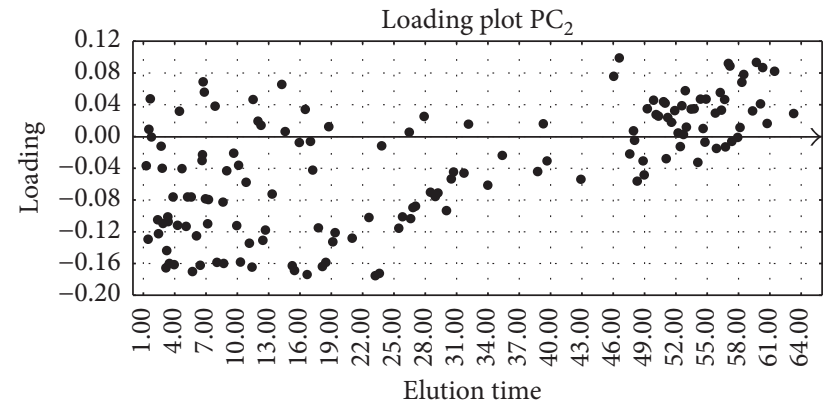

(b)

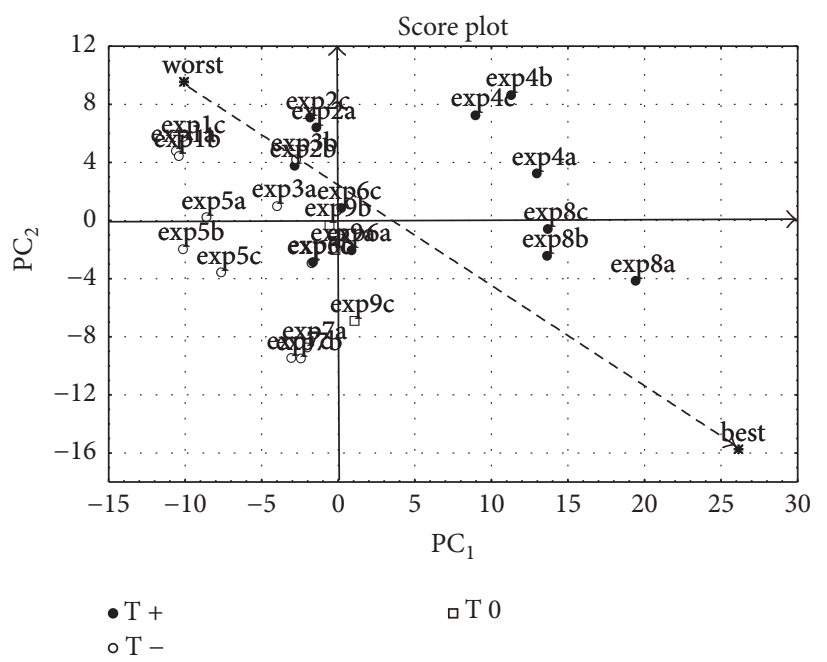

(c)

FIgURE 2: PCA results for signal intensity: loading plots for $\mathrm{PC}_{1}$ (a) and $\mathrm{PC}_{2}$ (b) and score plot of the first two PCs (c) with scores labeled according to extraction temperature. Experiments are numbered from 1 to 8 according to their order in Table 1; Exp 9 represents the center of the experimental domain. The last letter in the labels refers to the replication of the experimental design: "a," "b," or "c." 
TABLE 2: ANOVA table for signal intensity (a) and repeatability (b); $\mathrm{SS}=$ sum of squares; $\mathrm{df}=$ degrees of freedom; $F=$ calculated $F$-Fisher value; $p$-level $=$ calculated significance level.

(a) ANOVA: model for signal intensity

\begin{tabular}{lccccc}
\hline & SS & df & MS & $F$ & $p$-level \\
\hline$T$ & 388.88 & 1 & 388.88 & 80.20 & 0.0000 \\
$t$ & 656.79 & 1 & 656.79 & 135.46 & 0.0000 \\
salt & 240.95 & 1 & 240.95 & 49.70 & 0.0000 \\
Error & 106.67 & 22 & 4.85 & & \\
Total SS & 1404.79 & 26 & & & \\
\hline
\end{tabular}

(b) ANOVA: model for repeatability

\begin{tabular}{lccccc}
\hline & SS & df & MS & $F$ & $p$-level \\
\hline$t *$ salt & 218.23 & 1 & 218.23 & 15.05 & 0.0081 \\
$T * t *$ salt & 70.91 & 1 & 70.91 & 4.89 & 0.0689 \\
Error & 86.99 & 6 & 14.49 & & \\
Total SS & 376.13 & 8 & & & \\
\hline
\end{tabular}

the direction of optimization (dotted arrow). Exp 1 and Exp 2 are the closest to the worst: $\operatorname{Exp} 1$ is characterized by small areas of the peaks located both in the first (negative scores on $\mathrm{PC}_{2}$ ) and in the second (negative scores on $\mathrm{PC}_{1}$ ) part of the chromatogram. Exp 8 and Exp 4 are the best ones for what regards $\mathrm{PC}_{1}$ (larger areas for the peaks of the second part of the chromatogram), while Exp 7 is the best one for what regards the peaks eluting in the first half of the chromatogram. The first PC is mainly related to the effect played by extraction temperature and time (experiments with high extraction temperature and time are at positive scores along $\mathrm{PC}_{1}$ ): increasing temperature and time mainly plays a role on the peaks eluting in the second part of the chromatogram, as expected, since these compounds have higher boiling temperature and lower volatility. The second PC is instead mainly related to the effect played by salt (experiments with salt were at negative scores): salt plays a relevant effect mainly on the peaks eluting in the first half of the chromatogram.

The direction identified in the score plot between the "worst" and "best" experiments (dotted arrow in Figure 2(c)) represented the direction of the target function: the distance between each experiment and the "best" along the target function was used as a multivariate index of signal intensity and exploited to build a regression model relating signal intensity to the effect played by the examined factors.

Table 2(a) reports the ANOVA results obtained: only relevant effects are reported $(p$-level $<0.05)$. The final model contains only the principal effects: no second or third order interaction is significant and the model does not show a relevant curvature $(p$-level $=0.1379)$. Table $3(\mathrm{a})$ reports the coefficients of the final model together with their standard error and the corresponding $p$-level. The coefficients of the three factors show negative values, indicating that an increase of all the principal factors improves the experimental response. The final model shows a good fitting ability $\left(R^{2}\right.$ $=0.9158)$. The plot of the predicted versus the observed values (Figure 3(a)) confirms the good fitting ability, while the residuals (Figure 3(b)) show no significant trend. Figure 3(c)
TABLE 3: Regression results for the signal intensity (a) and repeatability (b) models: effects estimates and their standard error, $t$ Student calculated, significance $p$-level calculated, regression coefficients, and their standard error.

(a) Regression results: model of the signal intensity

\begin{tabular}{lcccccc}
\hline & Effect & $\begin{array}{c}\text { Std err } \\
\text { (effect) }\end{array}$ & $t$-Student & $p$-level Coeff & $\begin{array}{c}\text { Std err } \\
\text { (coeff) }\end{array}$ \\
\hline Mean/interc. & 30.40 & 0.44 & 69.8 & 0.000 & 30.40 & 0.44 \\
$T$ & -8.00 & 0.92 & -8.70 & 0.000 & -4.00 & 0.46 \\
$t$ & -10.40 & 0.92 & -11.3 & 0.000 & -5.20 & 0.46 \\
salt & -6.30 & 0.92 & -6.85 & 0.000 & -3.20 & 0.46 \\
\hline
\end{tabular}

(b) Regression results: model of the repeatability

\begin{tabular}{lcccccc}
\hline & Effect & $\begin{array}{c}\text { Std err } \\
(\text { effect) }\end{array}$ & $t$-Student & $p$-level & Coeff & $\begin{array}{c}\text { Std err } \\
(\text { coeff })\end{array}$ \\
\hline Mean/interc. & 11.0 & 1.3 & 8.75 & 0.000 & 11.0 & 1.3 \\
$t *$ salt & -10.0 & 2.7 & -3.88 & 0.008 & -5.0 & 1.3 \\
$T * t *$ salt & 6.0 & 2.7 & 2.21 & 0.069 & 3.0 & 1.3 \\
\hline
\end{tabular}

reports the response surface plot of signal intensity ( $z$-axis) as a function of temperature and time ( $x$ - and $y$-axes, resp.) when salt is at the highest level. The best overall conditions are obtained with all three factors at the highest level $(T=$ $70^{\circ} \mathrm{C}, t=60 \mathrm{~min}$, and salt $=27.50 \%$ ); either with or without the use of salt, a significant improvement in signal intensity can be reached when temperature and time are set at the highest level. The second best experiment within the experimental design is Exp 7 (temperature at low level, time at high level, and salt at high level).

Figure 4 reports the chromatograms obtained for Exp 8 and Exp 1, representing, respectively, the optimal and the worst experimental settings found in the experimental design: comparing the areas of the 143 identified peaks, more than $80 \%$ of the peaks show an increase in Exp 8 towards Exp 1 ; for about $54 \%$ the increase is two-fold and for $23 \%$, threefold, and the average value is about three-fold (with a maximum of 19 fold); Exp 1 shows a slight increase of some very early eluting peaks. Considering the signal intensity, the best conditions are those of $\operatorname{Exp} 8$ (extraction temperature: $70^{\circ} \mathrm{C}$; extraction time: $60 \mathrm{~min}$; and salt percentage: $27.50 \% \mathrm{w} / \mathrm{w}$ ).

4.3. Optimization of Repeatability. The three replications of each experiment of the design were used to estimate the experimental error (repeatability) in each condition of the experimental design. PCA was carried out on the $(9 \times 143)$ data matrix, 9 being the experiments of the experimental design and 143 the number of different $\mathrm{CV} \%$ s calculated, one for each chromatographic peak. The data were autoscaled before PCA. The loading and score plot of the first two PCs (explaining, resp., 32.87 and $21.06 \%$ of the overall variance) are reported in Figures 5(a)-5(c). As already described for signal intensity, the score plot reports also the "best" and the "worst" simulated experiments.

From the score plot it is possible to observe that the optimization direction, consisting, as before, in the direction 


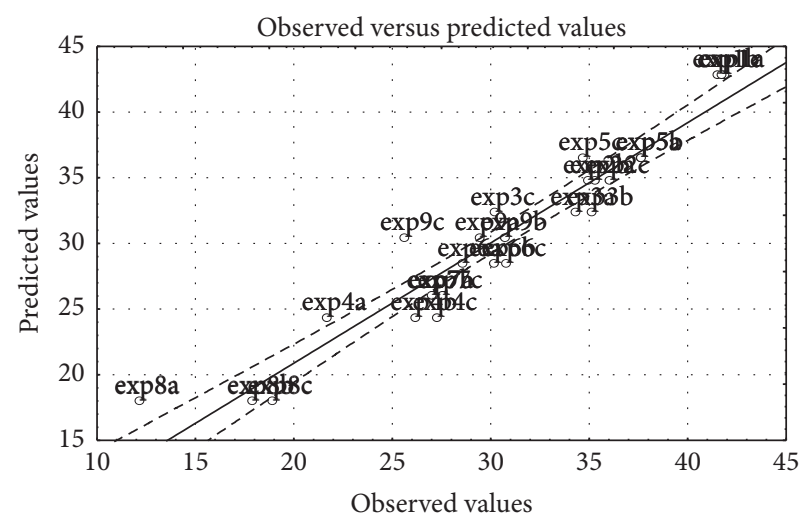

(a)

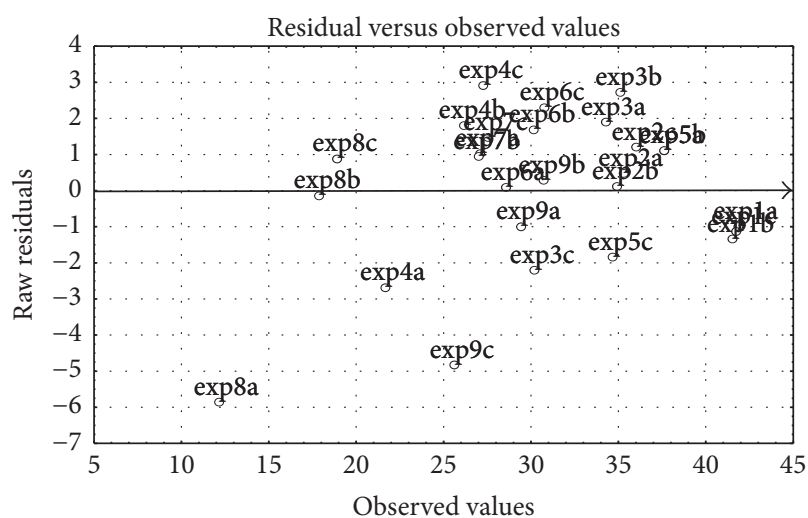

(b)

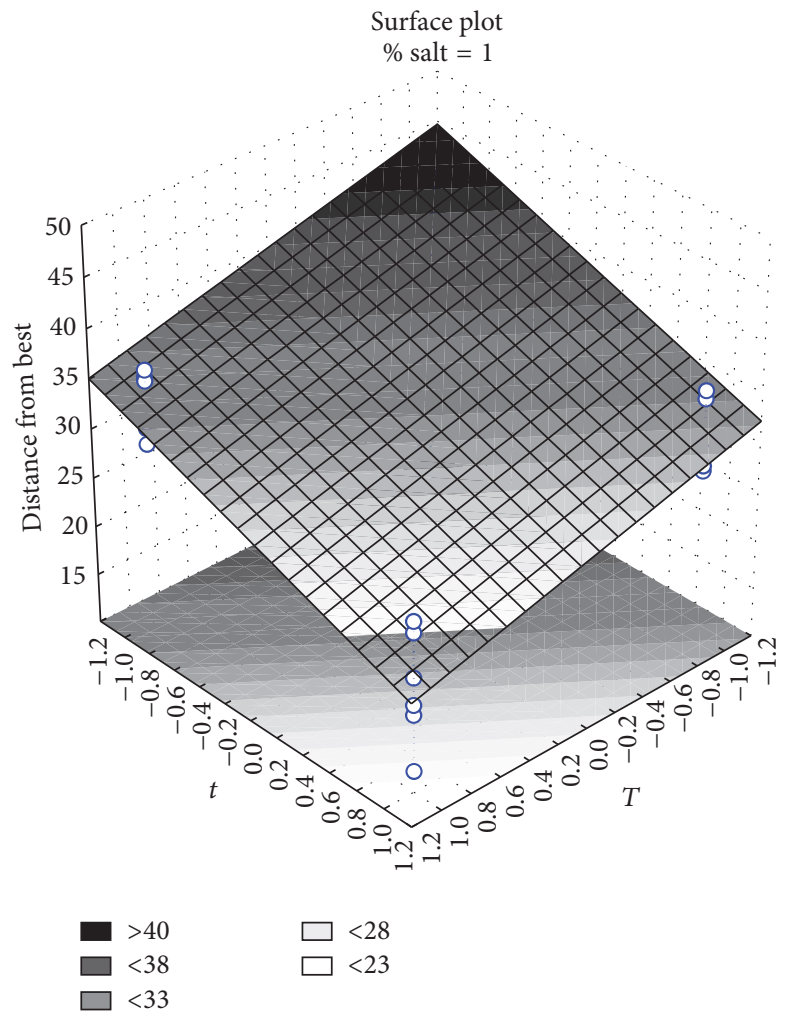

(c)

FiguRE 3: Model for signal intensity: predicted versus observed values (a), residuals versus observed values (b), and surface response for the interaction between temperature and time when salt is fixed at the highest level (c).

connecting the worst and best experiments, is represented by the first PC. The loading plot of the first PC shows most of the peaks with a large negative loading: experiments are therefore aligned along $\mathrm{PC}_{1}$ from negative to positive scores according to a decreasing $\mathrm{CV} \%$ value (i.e., increasing repeatability) for most of the peaks. The second PC accounts for the different behavior of the early eluting peaks (large positive loadings) and the last eluting ones (large negative loadings). Exp 7 and Exp 1 are therefore the best ones for what regards repeatability, showing the lowest overall CV\% value (large positive scores on $\mathrm{PC}_{1}$ ), while $\operatorname{Exp} 5$ is the worst (largest negative scores on $\mathrm{PC}_{1}$ ). Exp 2 and 5 are the most different according to $\mathrm{PC}_{2}$ : Exp 2 shows a repeatability in general above the average but its experimental conditions are particularly effective in improving repeatability of the last eluting peaks; Exp 5 is the overall worst experiment of the design but, according to $\mathrm{PC}_{2}$, shows a behavior opposite to Exp 2. According to the second PC, among the experiments with an overall repeatability above the average, Exp 1, Exp 7, and Exp 8 improve in particular the repeatability of the early eluting peaks, while Exp 2 and Exp 6 show an opposite behavior. Anyway, the first PC is sufficient as the target function, $\mathrm{PC}_{2}$ showing a negligible effect: the distance of the experiments from the best along $\mathrm{PC}_{1}$ was therefore used for building a model for repeatability. Table 2(b) shows the results obtained for ANOVA, while Table 3(b) reports the 


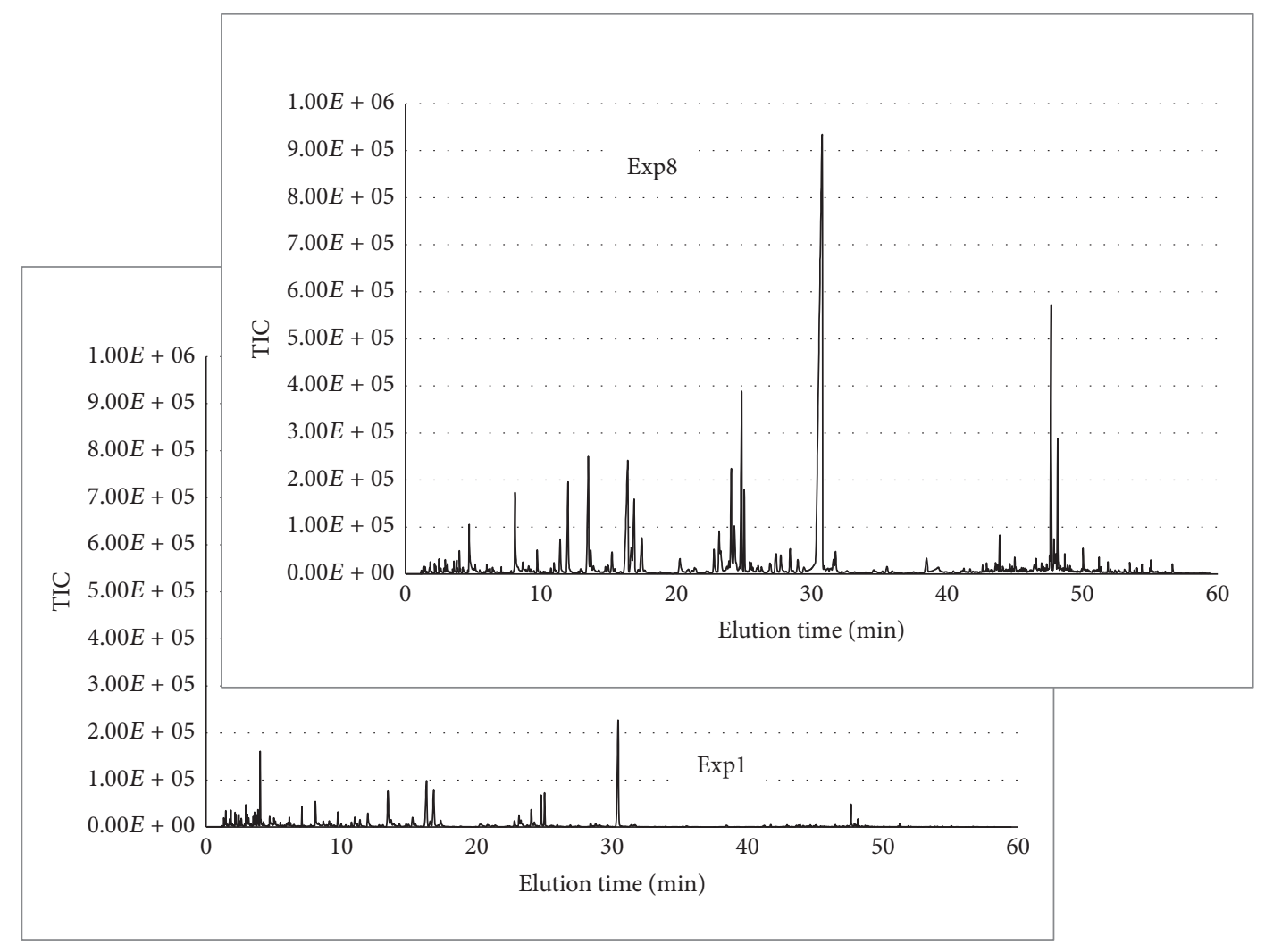

FIGURE 4: TIC chromatogram for Exp 1 (extraction temperature: $50^{\circ} \mathrm{C}$, extraction time: $20 \mathrm{~min}$, and no salt) and Exp 8 (extraction temperature: $70^{\circ} \mathrm{C}$, extraction time: $60 \mathrm{~min}, 27.50 \% \mathrm{w} / \mathrm{w}$ of salt). Other details for the analytical method are reported in the experimental sections.

coefficients of the relevant effects together with their $p$-level and their standard deviation.

The final model shows an acceptable fitting ability $\left(R^{2}\right.$ $=0.7687$ ) allowing a discussion of the effects played by the factors on repeatability, devoted to the identification of the best operative conditions.

The final model contains the interaction between time and salt and the three-way interaction: this last one was retained as significant since it shows a $p$-level quite close to 0.05 . The coefficient of the interaction between time and salt shows a negative coefficient, while the three-way interaction shows a positive coefficient. Figure 5(d) represents the threeway interaction: the experimental results obtained in terms of distance of each experiment from the best along the optimization direction are reported on a cube representing the experimental domain where each dimension corresponds to one of the investigated factors. When salt is not added, the best repeatability is obtained with a short extraction time, regardless of the level of temperature adopted. When salt is added instead and when temperature is low, increasing the extraction time strongly increases repeatability, which is slightly reduced with time at high temperature. On the other hand, with a short extraction time an increase in temperature strongly improves repeatability, while an opposite effect is recorded with a long extraction time. The overall best conditions correspond to $\operatorname{Exp} 7\left(T=50^{\circ} \mathrm{C}, t=60 \mathrm{~min}\right.$, and salt $=27.5 \%)$. Table 4 resumes the repeatability results obtained for each experiment: each column reports the \% of peaks in
TABLE 4: Results obtained for repeatability for the experiments of the experimental design: \% of peaks in the chromatogram with CV\% smaller than $5 \%, 10 \%, 20 \%$, and $30 \%$. Results in bold represent the maxima recorded for each threshold level.

\begin{tabular}{lcccc}
\hline & \% CV $<5 \%$ & \% CV $<10 \%$ & $\% \mathrm{CV}<20 \%$ & $\% \mathrm{CV}<30 \%$ \\
\hline Exp 1 & 16 & 45 & $\mathbf{7 3}$ & $\mathbf{8 6}$ \\
Exp 2 & 21 & 42 & 63 & 76 \\
Exp 3 & 3.4 & 12 & 39 & 66 \\
Exp 4 & 2.1 & 20 & 51 & 72 \\
Exp 5 & 2.1 & 14 & 46 & 72 \\
Exp 6 & 16 & 45 & 66 & 79 \\
Exp 7 & $\mathbf{4 3}$ & $\mathbf{6 6}$ & $\mathbf{7 7}$ & $\mathbf{8 4}$ \\
Exp 8 & 5.5 & 29 & $\mathbf{7 6}$ & $\mathbf{8 7}$ \\
Exp 9 & 2.7 & 18 & 51 & $\mathbf{8 3}$ \\
\hline
\end{tabular}

the chromatogram of the corresponding experiment showing a CV\% smaller than four selected thresholds. As expected, Exp 7 (extraction temperature: $50^{\circ} \mathrm{C}$; extraction time: $60 \mathrm{~min}$; salt percentage: $27.50 \% \mathrm{w} / \mathrm{w}$ ) provides the best results for the optimization of repeatability, showing more than $40 \%$ of peaks with a CV\% smaller than $5 \%$.

4.4. Best Compromise. It is useful to identify the experimental conditions allowing achievement of the best compromise between high signal intensity and high repeatability. To this purpose, the experiments of the experimental design can be 


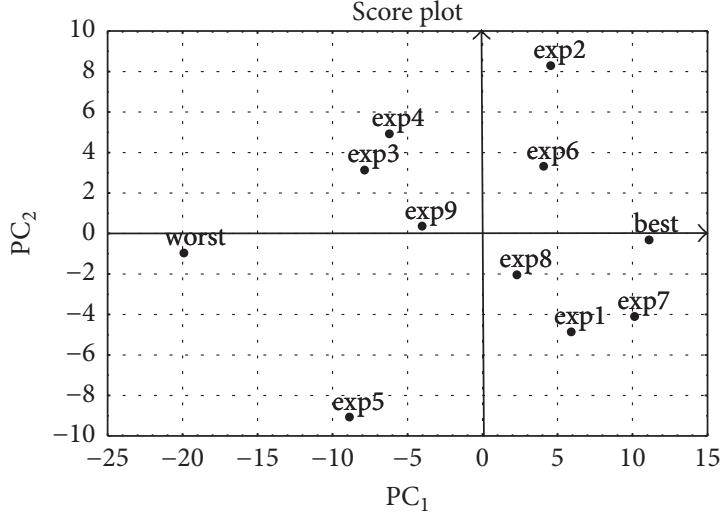

(a)

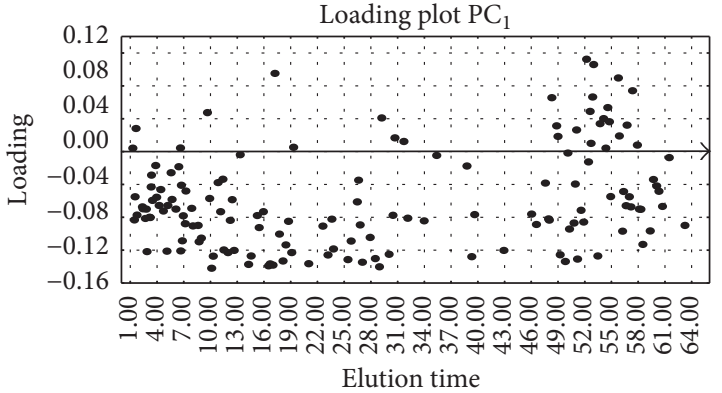

(b)

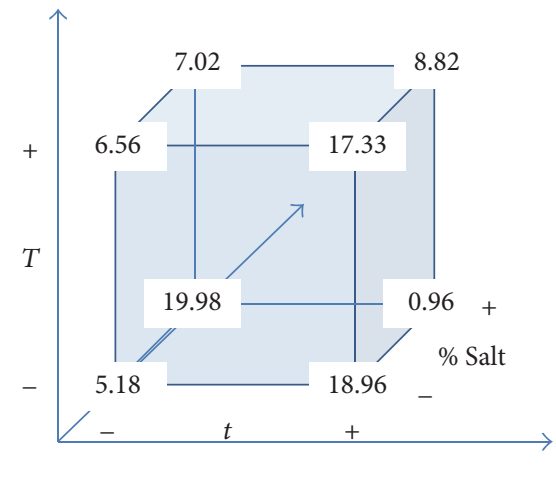

(d)

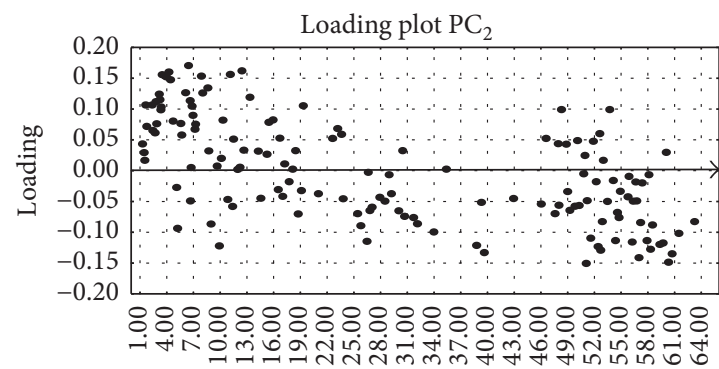

Elution time

(c)

FIGURE 5: Results for repeatability: score plot of the first two PCs (a) and loading plots for $\mathrm{PC}_{1}(\mathrm{~b})$ and $\mathrm{PC}_{2}$ (c); representation of the three-way interaction (d). Experiments are numbered from 1 to 8 according to their order in Table 1; Exp 9 represents the center of the experimental domain.

plotted as a function of their signal intensity and repeatability (Figure 6(a)). The scatter plot reports the repeatability of each experiment of the experimental design on the $y$-axis, expressed as distance from "best" along the first PC. Signal intensity is instead reported as the average distance from "best" in the space given by the first two PCs calculated over the three replications of the same experimental conditions. The plot shows also the best and the worst simulated experiments. Both repeatability and signal intensity are reported as range-scaled values computed with respect to "worst" and "best," respectively. The experimental conditions corresponding to the best compromise between optimization of signal intensity and of repeatability correspond to the experiment closest to "best."

Exp 8 and 7 appear as the best results: Exp 8 is the closest to "best" (distance $=0.96$ ), while the extraction conditions adopted in Exp 7 provide a larger improvement of repeatability rather than of signal intensity (distance from the best $=1.23$ ). The final global best compromise is therefore reached with the experimental settings of Exp 8 (extraction temperature: $70^{\circ} \mathrm{C}$; extraction time: $60 \mathrm{~min}$; salt percentage: $27.50 \% \mathrm{w} / \mathrm{w})$.
4.5. Exploration of the Experimental Domain around the Optimal Conditions. Since the optimal experimental conditions identified, corresponding to Exp 8, are located at an extreme of the experimental domain, it is necessary to explore the experimental domain close to Exp 8 to check the model stability even outside the domain initially investigated. Therefore, three experiments were carried out: $\operatorname{Exp} 8, \operatorname{Exp} 8-$, and Exp 8+ (each experiment was replicated three times). Exp 8- $\left(T=65^{\circ} \mathrm{C}, t=55 \mathrm{~min}\right.$, and salt $\left.=24 \%\right)$ is located within the initial experimental domain, while Exp $8+(T$ $=75^{\circ} \mathrm{C}, t=65 \mathrm{~min}$, and salt $=31 \%$ ) is located outside the experimental domain; both experiments lay along the direction of optimization identified by the model. Figures 6(b) and $6(\mathrm{c})$ report the results obtained for signal intensity (b) and repeatability (c): the experiments are reported on the $x$-axis, while their distance from "best" is on the $y$-axis. As for signal intensity, the results show an improvement passing from Exp 8- to Exp 8 and Exp 8+, while there is no statistically significant difference between the three experiments regarding repeatability. Exp 8 does not represent a global optimum for signal intensity but its experimental conditions can be effectively applied since they represent a reasonable 


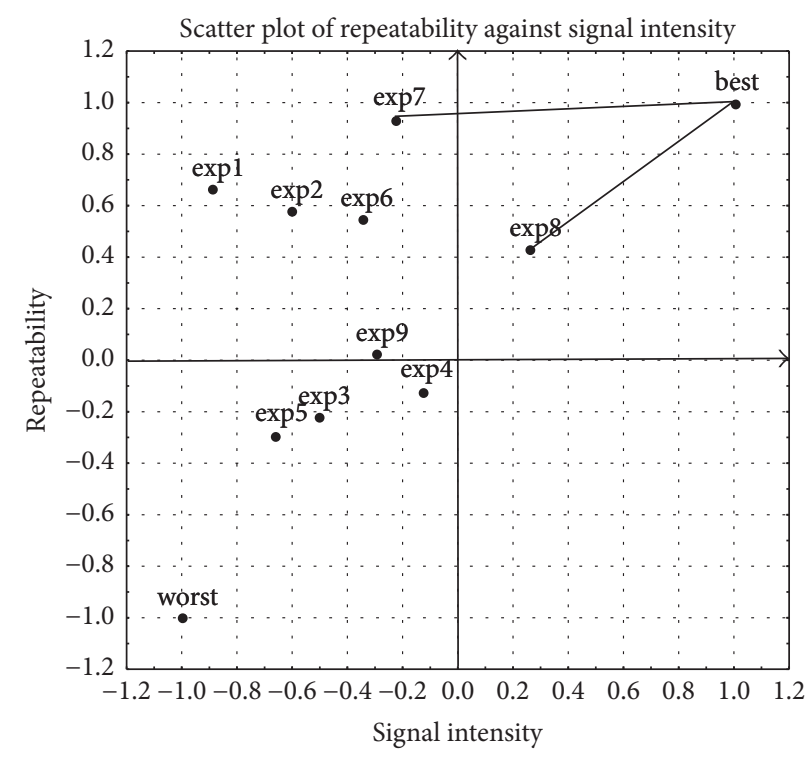

(a)

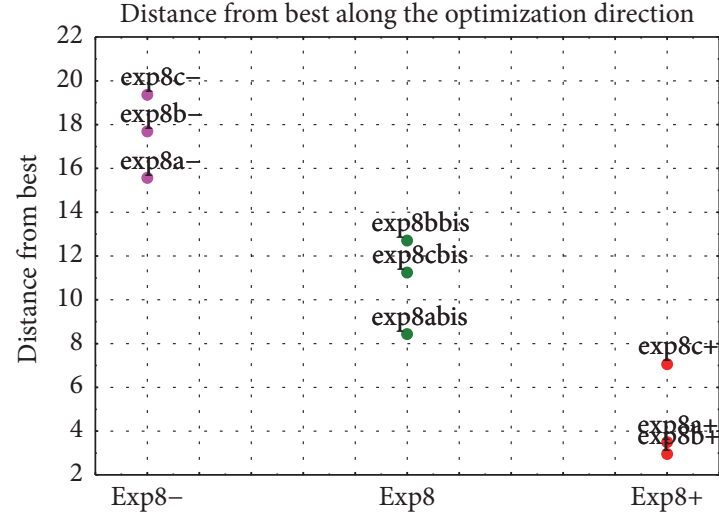

(b)

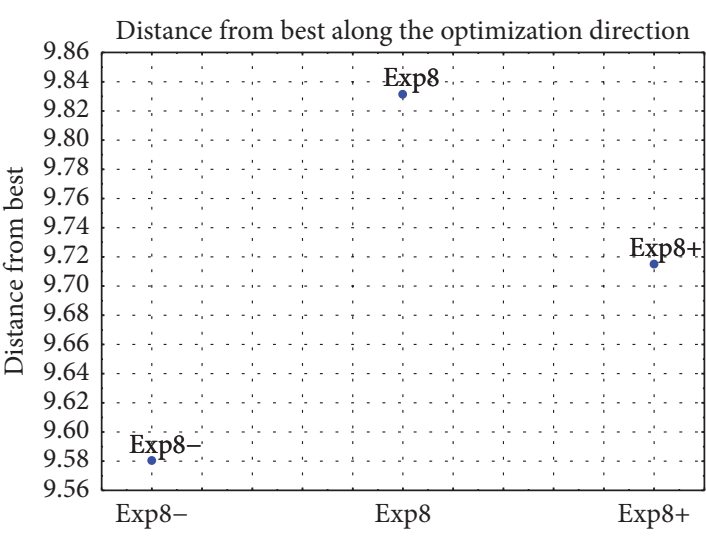

(c)

FIGURE 6: Repeatability versus signal intensity: identification of the best compromise between signal intensity and repeatability optimization (a). Exploration of the experimental domain around Exp 8: signal intensity (expressed as distance from best) (b) and repeatability (expressed as distance from best) (c) for Exp 8-, Exp 8, and Exp 8+. Experimental conditions were reported in Section 4.5.

compromise with time of analysis; moreover, repeatability is stable in the neighborhoods of Exp 8 and the linear model built for signal intensity is still valid in the region explored outside the initial experimental domain.

4.6. Choice of the Suitable Internal Standard. Some considerations can also be drawn about the choice of the suitable internal standard (IS). Here, three compounds were tested: o-tolualdehyde $\left(t_{r} \sim 15 \mathrm{~min}\right), 2,4,6$-trimethylphenol $\left(t_{r} \sim\right.$ $27 \mathrm{~min})$, and benzophenone $\left(t_{r} \sim 54 \mathrm{~min}\right)$. The effectiveness of the three IS selected was tested by calculating the CV\% of each peak from the peak areas normalized in turn for each of the available IS. The results are reported in Figure 7 for Exp 7 and Exp 8, considering three different time ranges in the chromatogram. Figure 7 reports for each case the $\%$ of peaks with CV\% smaller than selected threshold values, namely, 2 , 5,10 , and $20 \%$.
For the early eluting peaks (0-20 min; Figure 7(a)), 2,4,6trimethylphenol (indicated as "trime") seems the best choice, providing the largest \% of peaks with small CV\%; in particular, when it is used as IS in this time range, Exp 7 shows better results than Exp 8. For the intermediate part of the chromatogram (20-40 min; Figure 7(b)), 2,4,6-trimethylphenol is again the best choice but, in this case, its use as IS provides similar results for Exp 7 and Exp 8. Finally, for the last eluting peaks (40 min-end; Figure 7(c)), benzophenone (indicated as "benzo") is the best alternative and again Exp 7 and Exp 8 show similar results. O-Tolualdehyde (indicated as "o-tolu") never represents the best choice. So, two different IS can be used for peak area normalization: 2,4,6-Trimethylphenol for peaks eluting before $40 \mathrm{~min}$ and benzophenone for the last eluting ones. When IS are used for peak area normalization, Exp 7 and Exp 8 show similar behavior concerning repeatability: this consideration further confirms 


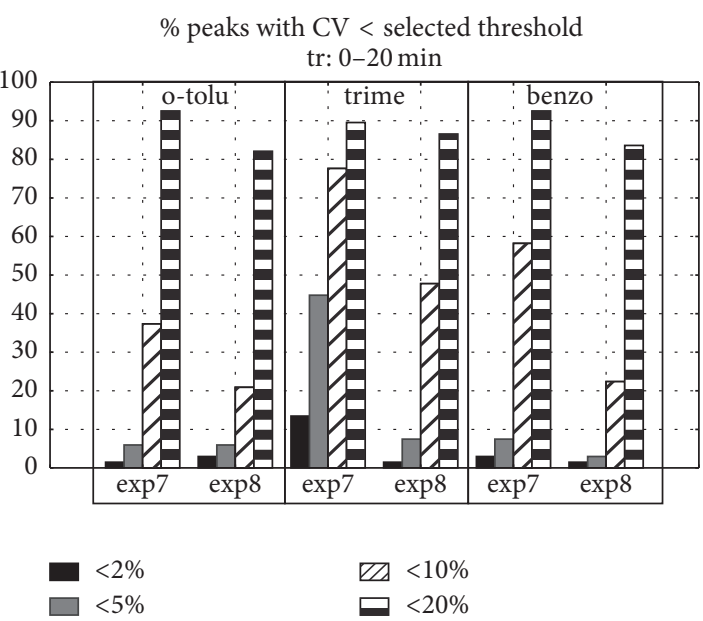

(a)

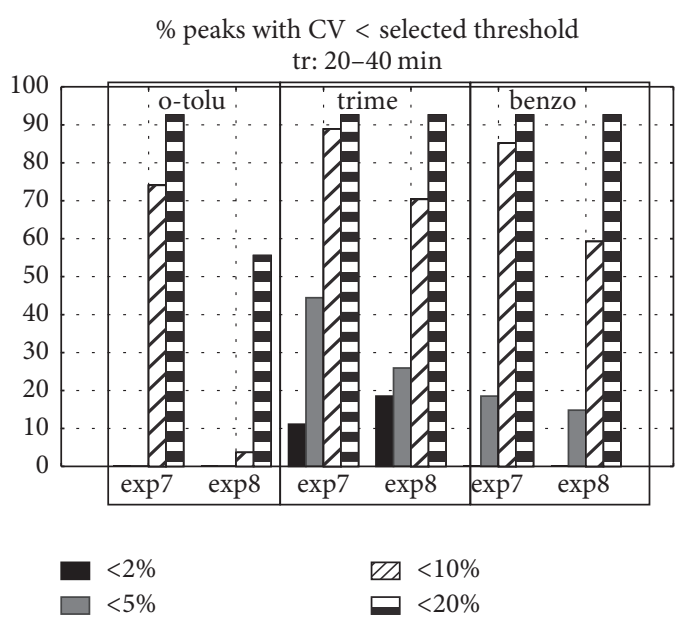

(b)

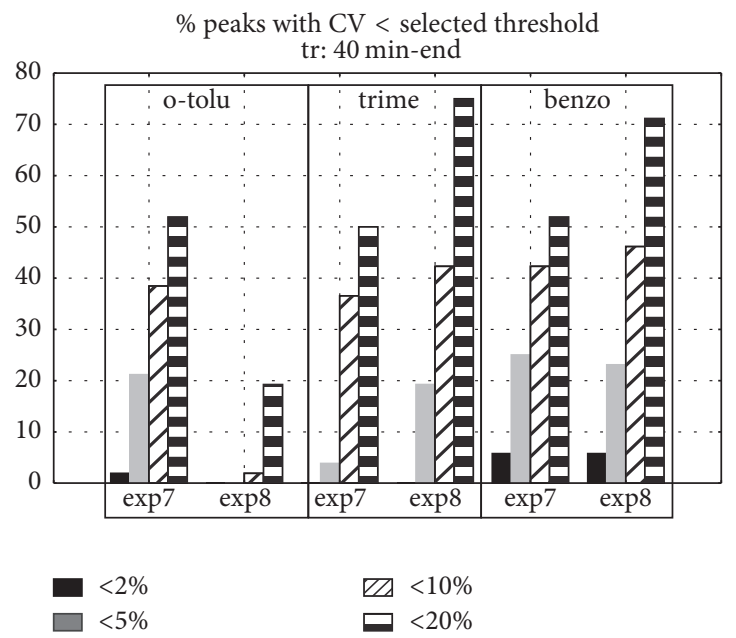

(c)

Figure 7: Comparison of three I.S.: \% of peaks with CV\% less than selected threshold levels (2, 5, 10, and 20) when o-tolualdehyde (o-tolu), 2,4,6-trimethylphenol (trime), and benzophenone (benzo) are used as I.S. for area correction: peaks eluting in the range 0-20 min (a), 20$40 \mathrm{~min}(\mathrm{~b})$, and $40 \mathrm{~min}$-end (c). The results are represented for $\operatorname{Exp} 7\left(\mathrm{~T}=60^{\circ} \mathrm{C}, t=60 \mathrm{~min}\right.$, and salt $\left.=27.5 \%\right)$ and $\operatorname{Exp} 8\left(T=70^{\circ} \mathrm{C}, t=60 \mathrm{~min}\right.$, and salt $=27.5 \%)$.

that the identification of Exp 8 conditions as the global optimal ones is a good choice.

4.7. GC-MS Analysis. The optimized conditions of SPME and GC-MS were applied to the analysis of an organic commercial multiflower honey sample. From the results, a total of 143 peaks corresponding to 143 molecules were identified and reported in Table S1 in Supplementary Material available online at https://doi.org/10.1155/2017/6437857. Each species was identified by the comparison of its experimental mass spectrum with those present in the NIST 2.0 library and compared by the use of standards, if present. The identified molecules belonged to different classes as carboxylic acids (that give a "buttery" flavor), alcohols, aldehydes (associated to a "caramel" flavor), ketones, terpenes, esters, norisoprenoid, and furan derivatives. The presence of branched aldehydes as 2-methyl-butanal and 2-methyl-propanal can derive from the metabolism of aminoacids and from the fermentation by the action of yeasts, generally accepted in honey. The presence of short chain and branched alcohols (as 1-butanol and 3-buten-1-ol-3-methyl) can derive from the Maillard's reaction that takes place during honey storage and processing, while furfural and $2(3 \mathrm{H})$-furanone5-ethenyldihydro-5-methyl derived from nonenzymatic browning reactions. The identification of terpenes as $\alpha$ terpinene and $\tau$-terpinene is associated to the floral nectar of honeydew gathered by honeybees $[55,56]$.

\section{Conclusions}

Optimization of SPME of honey samples was carried out here considering both signal intensity (expressed as chromatographic peak areas) and repeatability (expressed as the variation of each peak area across replications of the same 
experiment) by means of experimental design, studying the effect of three factors: temperature of extraction, time of extraction, and the amount of salt added to the sample. Each experiment was evaluated by a multivariate target function based on PCA, taking into account all the analytes at the same time. For both signal intensity and repeatability, a multivariate target function was defined in the space given by the significant PCs. The position of each experiment along the target function was therefore used as response to build regression models relating signal intensity and repeatability to the effects played by the relevant factors and/or their interactions. A model with good fitting ability was achieved for signal intensity, while the model for repeatability proved to be suitable for a general discussion of the effects played by the relevant factors. Optimal experimental conditions were finally identified as the best compromise between repeatability and signal intensity optimization: temperature of extraction at $70^{\circ} \mathrm{C}$, time of extraction at $60 \mathrm{~min}$, and $27.50 \% \mathrm{w} / \mathrm{w}$ of salt. It was also possible to identify the most suitable internal standards, namely, 2,4,6-trimethylphenol, which proved to be the best choice for peaks eluting before $40 \mathrm{~min}$ and benzophenone, that was optimal for the last eluting ones.

The optimized method was used for the SPME GC-MS analysis of a multiflower honey sample and more than a hundred compounds were identified.

The proposed multivariate approach represents an effective approach that can be adopted to accomplish multivariate optimization when solid phase microextraction has to be applied. The main advantage of this procedure is the achievement of global optimal experimental conditions providing the optimization of both signal intensity and repeatability; this is particularly important since low repeatability is one of the most serious drawbacks in SPME. The results obtained for what regards the experimental conditions identified as the best ones are in agreement with similar procedures reported in literature. Here we also provide indication about the best internal standard to be adopted, while in literature one single I.S. or no I.S. at all is used for volatiles extraction from honey samples by SPME.

\section{Competing Interests}

The authors declare that there is no conflict of interests regarding the publication of this paper.

\section{Acknowledgments}

The authors gratefully acknowledge support from Ministero della Sanità, Italy (Ricerca Finalizzata, Project PRF2009201, "untargeted approach in detecting food adulteration and contamination using spectroscopic techniques database and chemometrics").

\section{References}

[1] E. Ranzato, S. Martinotti, and B. Burlando, "Epithelial mesenchymal transition traits in honey-driven keratinocyte wound healing: comparison among different honeys," Wound Repair and Regeneration, vol. 20, no. 5, pp. 778-785, 2012.
[2] N. J. Basson and S. R. Grobler, "Antimicrobial activity of two South African honeys produced from indigenous Leucospermum cordifolium and Erica species on selected micro-organisms," BMC Complementary and Alternative Medicine, vol. 8, article no. 41, 2008.

[3] A. B. Jull, N. Walker, and S. Deshpande, "Honey as a topical treatment for wounds," Cochrane Database of Systematic Reviews, vol. 2, Article ID CD005083, 2013.

[4] L. Castro-Vázquez, V. Leon-Ruiz, M. E. Alañon, M. S. PérezCoello, and A. V. González-Porto, "Floral origin markers for authenticating Lavandin honey (Lavandula angustifolia $x$ latifolia). Discrimination from Lavender honey (Lavandula latifolia)," Food Control, vol. 37, no. 1, pp. 362-370, 2014.

[5] A. Agila and S. Barringer, "Effect of adulteration versus storage on volatiles in Unifloral Honeys from different floral sources and locations," Journal of Food Science, vol. 78, no. 2, pp. C184C191, 2013.

[6] I. Špánik, A. Janáčová, Z. Šusterová et al., "Characterisation of VOC composition of Slovak monofloral honeys by GC $\times$ GCTOF-MS," Chemical Papers, vol. 67, no. 2, pp. 127-134, 2013.

[7] Y. Yang, M.-J. Battesti, J. Paolini, A. Muselli, P. Tomi, and J. Costa, "Melissopalynological origin determination and volatile composition analysis of Corsican "Erica arborea spring maquis" honeys," Food Chemistry, vol. 134, no. 1, pp. 37-47, 2012.

[8] V. Kaškoniene and P. R. Venskutonis, "Floral markers in honey of various botanical and geographic origins: a review," Comprehensive Reviews in Food Science and Food Safety, vol. 9, no. 6, pp. 620-634, 2010.

[9] E. Alissandrakis, E. Mantziaras, P. A. Tarantilis, P. C. Harizanis, and M. Polissiou, "Generation of linalool derivatives in an artificial honey produced from bees fed with linalool-enriched sugar syrup," European Food Research and Technology, vol. 231, no. 1, pp. 21-25, 2010.

[10] D. Mannaş and T. Altuğ, "SPME/GC/MS and sensory flavour profile analysis for estimation of authenticity of thyme honey," International Journal of Food Science and Technology, vol. 42, no. 2, pp. 133-138, 2007.

[11] C. Guyot-Declerck, S. Renson, A. Bouseta, and S. Collin, "Floral quality and discrimination of Lavandula stoechas, Lavandula angustifolia, and Lavandula angustifolia x latifolia honeys," Food Chemistry, vol. 79, no. 4, pp. 453-459, 2002.

[12] T. Dymerski, T. Chmiel, A. Mostafa et al., "Botanical and geographical origin characterization of Polish honeys by headspace SPME-GC× GC-TOFMS," Current Organic Chemistry, vol. 17, no. 8, pp. 853-870, 2013.

[13] G. Papotti, D. Bertelli, and M. Plessi, "Use of HS-SPME-GCMS for the classification of Italian lemon, orange and citrus spp. honeys," International Journal of Food Science and Technology, vol. 47, no. 11, pp. 2352-2358, 2012.

[14] L. Cuevas-Glory, E. Ortiz-Vázquez, J. A. Pino, and E. SauriDuch, "Floral classification of Yucatan Peninsula honeys by PCA \& HS-SPME/GC-MS of volatile compounds," International Journal of Food Science and Technology, vol. 47, no. 7, pp. 1378-1383, 2012.

[15] I. Escriche, M. Kadar, M. Juan-Borrás, and E. Domenech, "Using flavonoids, phenolic compounds and headspace volatile profile for botanical authentication of lemon and orange honeys," Food Research International, vol. 44, no. 5, pp. 1504-1513, 2011.

[16] I. Stanimirova, B. Üstün, T. Cajka et al., "Tracing the geographical origin of honeys based on volatile compounds profiles 
assessment using pattern recognition techniques," Food Chemistry, vol. 118, no. 1, pp. 171-176, 2010.

[17] E. de la Fuente, R. M. Valencia-Barrera, I. Martínez-Castro, and J. Sanz, "Occurrence of 2-hydroxy-5-methyl-3-hexanone and 3hydroxy-5-methyl-2-hexanone as indicators of botanic origin in eucalyptus honeys," Food Chemistry, vol. 103, no. 4, pp. 11761180, 2007.

[18] E. de la Fuente, I. Martínez-Castro, and J. Sanz, "Characterization of Spanish unifloral honeys by solid phase microextraction and gas chromatography-mass spectrometry," Journal of Separation Science, vol. 28, no. 9-10, pp. 1093-1100, 2005.

[19] L. Piasenzotto, L. Gracco, and L. Conte, "Solid phase microextraction (SPME) applied to honey quality control," Journal of the Science of Food and Agriculture, vol. 83, no. 10, pp. 1037-1044, 2003.

[20] N. Jánošková, O. Vyviurska, and I. Špánik, "Identification of volatile organic compounds in honeydew honeys using comprehensive gas chromatography," Journal of Food and Nutrition Research, vol. 53, no. 4, pp. 353-362, 2014.

[21] A. Romano, M. Cuenca, S. Makhoul et al., "Comparison of eNoses: the case study of honey," Italian Journal of Food Science, vol. 28, no. 2, pp. 326-337, 2016.

[22] M. Moniruzzaman, I. Rodríguez, M. Ramil, R. Cela, S. A. Sulaiman, and S. H. Gan, "Assessment of gas chromatography time-of-flight accurate mass spectrometry for identification of volatile and semi-volatile compounds in honey," Talanta, vol. 129, pp. 505-515, 2014.

[23] M. Pontes, J. C. Marques, and J. S. Câmara, "Screening of volatile composition from Portuguese multifloral honeys using headspace solid-phase microextraction-gas chromatographyquadrupole mass spectrometry," Talanta, vol. 74, no. 1, pp. 91103, 2007.

[24] F. Pasini, S. Gardini, G. L. Marcazzan, and M. F. Caboni, "Buckwheat honeys: screening of composition and properties," Food Chemistry, vol. 141, no. 3, pp. 2802-2811, 2013.

[25] I. Jerković, A. Kasum, Z. Marijanović, and C. I. G. Tuberoso, "Contribution to the characterisation of honey-based Sardinian product abbamele: volatile aroma composition, honey marker compounds and antioxidant activity," Food Chemistry, vol. 124, no. 1, pp. 401-410, 2011.

[26] A. C. Soria, J. Sanz, and I. Martínez-Castro, "SPME followed by GC-MS: a powerful technique for qualitative analysis of honey volatiles," European Food Research and Technology, vol. 228, no. 4, pp. 579-590, 2009.

[27] A. C. Soria, I. Martínez-Castro, C. de Lorenzo, and J. Sanz, "Occurrence of nitriles in Taraxacum labelled honeys," Food Chemistry, vol. 107, no. 1, pp. 439-443, 2008.

[28] N. Campillo, P. Viñas, R. Peñalver, J. I. Cacho, and M. Hernández-Córdoba, "Solid-phase microextraction followed by gas chromatography for the speciation of organotin compounds in honey and wine samples: a comparison of atomic emission and mass spectrometry detectors," Journal of Food Composition and Analysis, vol. 25, no. 1, pp. 66-73, 2012.

[29] G. Papotti, D. Bertelli, M. Lolli, A. G. Sabatini, and M. Plessi, "Methyl anthranilate content in Italian citrus honeys determined by HS-SPME-GC," International Journal of Food Science and Technology, vol. 44, no. 10, pp. 1933-1938, 2009.

[30] D. Bertelli, G. Papotti, M. Lolli, A. G. Sabatini, and M. Plessi, "Development of an HS-SPME-GC method to determine the methyl anthranilate in Citrus honeys," Food Chemistry, vol. 108, no. 1, pp. 297-303, 2008.
[31] A. C. Soria, M. González, C. De Lorenzo, I. Martínez-Castro, and J. Sanz, "Estimation of the honeydew ratio in honey samples from their physicochemical data and from their volatile composition obtained by SPME and GC-MS," Journal of the Science of Food and Agriculture, vol. 85, no. 5, pp. 817-824, 2005.

[32] B. Plutowska, T. Chmiel, T. Dymerski, and W. Wardencki, "A headspace solid-phase microextraction method development and its application in the determination of volatiles in honeys by gas chromatography," Food Chemistry, vol. 126, no. 3, pp. 12881298, 2011.

[33] Q. L. Ma, N. Hamid, A. E. D. Bekhit, J. Robertson, and T. F. Law, "Optimization of headspace solid phase microextraction (HSSPME) for gas chromatography mass spectrometry (GC-MS) analysis of aroma compounds in cooked beef using response surface methodology," Microchemical Journal, vol. 111, pp. 1624, 2013.

[34] E. Paula Barros, N. Moreira, G. Elias Pereira, S. G. F. Leite, C. Moraes Rezende, and P. Guedes De Pinho, "Development and validation of automatic HS-SPME with a gas chromatographyion trap/mass spectrometry method for analysis of volatiles in wines," Talanta, vol. 101, pp. 177-186, 2012.

[35] G. Basaglia and M. C. Pietrogrande, "Optimization of a SPME/ GC/MS method for the simultaneous determination of pharmaceuticals and personal care products in waters," Chromatographia, vol. 75, no. 7-8, pp. 361-370, 2012.

[36] P. C. F. De Lima Gomes, J. Y. Barletta, C. E. D. Nazario et al., "Optimization of in situ derivatization SPME by experimental design for GC-MS multi-residue analysis of pharmaceutical drugs in wastewater," Journal of Separation Science, vol. 34, no. 4, pp. 436-445, 2011.

[37] C. Pizarro, N. Pérez-del-Notario, and J. M. González-Sáiz, "Optimisation of a simple and reliable method based on headspace solid-phase microextraction for the determination of volatile phenols in beer," Journal of Chromatography A, vol. 1217, no. 39, pp. 6013-6021, 2010.

[38] J. Januszkiewicz, H. Sabik, S. Azarnia, and B. Lee, "Optimization of headspace solid-phase microextraction for the analysis of specific flavors in enzyme modified and natural Cheddar cheese using factorial design and response surface methodology," Journal of Chromatography A, vol. 1195, no. 1-2, pp. 16-24, 2008.

[39] J. Salafranca, C. Domeño, C. Fernández, and C. Nerín, "Experimental design applied to the determination of several contaminants in Duero River by solid-phase microextraction," Analytica Chimica Acta, vol. 477, no. 2, pp. 257-267, 2003.

[40] A. Asfaram, M. Ghaedi, A. Goudarzi, M. Soylak, and S. Mehdizadeh Langroodi, "Magnetic nanoparticle based dispersive micro-solid-phase extraction for the determination of malachite green in water samples: optimized experimental design," New Journal of Chemistry, vol. 39, no. 12, pp. 9813-9823, 2015.

[41] A. Asfaram, M. Ghaedi, A. Goudarzi, and M. Soylak, "Comparison between dispersive liquid-liquid microextraction and ultrasound-assisted nanoparticles-dispersive solid-phase microextraction combined with microvolume spectrophotometry method for the determination of Auramine-O in water samples," RSC Advances, vol. 5, no. 49, pp. 39084-39096, 2015.

[42] S. Bahrani, M. Ghaedi, M. J. Mansoorkhani, A. Asfaram, A. A. Bazrafshan, and M. K. Purkait, "Ultrasonic assisted dispersive solid-phase microextraction of eriochrome cyanine R from water sample on ultrasonically synthesized lead (II) dioxide nanoparticles loaded on activated carbon: experimental design methodology," Ultrasonics Sonochemistry, vol. 34, pp. 317-324, 2017. 
[43] A. Asfaram, M. Ghaedi, and A. Goudarzi, "Optimization of ultrasound-assisted dispersive solid-phase microextraction based on nanoparticles followed by spectrophotometry for the simultaneous determination of dyes using experimental design," Ultrasonics Sonochemistry, vol. 32, pp. 407-417, 2016.

[44] J. N. Bianchin, G. Nardini, J. Merib, A. N. Dias, E. Martendal, and E. Carasek, "Screening of volatile compounds in honey using a new sampling strategy combining multiple extraction temperatures in a single assay by HS-SPME-GC-MS," Food Chemistry, vol. 145, pp. 1061-1065, 2014.

[45] L. Ceballos, J. A. Pino, C. E. Quijano-Celis, and A. Dago, "Optimization of a HS-SPME/GC-MS method for determination of volatile compounds in some cuban unifloral honeys," Journal of Food Quality, vol. 33, no. 4, pp. 507-528, 2010.

[46] F. Pellati, S. Benvenuti, F. Yoshizaki, D. Bertelli, and M. C. Rossi, "Headspace solid-phase microextraction-gas chromatographymass spectrometry analysis of the volatile compounds of Evodia species fruits," Journal of Chromatography A, vol. 1087, no. 1-2, pp. 265-273, 2005.

[47] S. Furlanetto, S. Orlandini, P. Mura, M. Sergent, and S. Pinzauti, "How experimental design can improve the validation process. Studies in pharmaceutical analysis," Analytical and Bioanalytical Chemistry, vol. 377, no. 5, pp. 937-944, 2003.

[48] M. M. Bravo, A. S. Valenzuela, E. P. Fuentes, and W. V. Quiroz, "Critical evaluation of fiber coatings for organotin determination by using solid phase microextraction in headspace mode," Journal of Chromatography A, vol. 1223, pp. 9-14, 2012.

[49] J. S. Ribeiro, R. F. Teófilo, F. Augusto, and M. M. C. Ferreira, "Simultaneous optimization of the microextraction of coffee volatiles using response surface methodology and principal component analysis," Chemometrics and Intelligent Laboratory Systems, vol. 102, no. 1, pp. 45-52, 2010.

[50] E. Robotti, F. Gosetti, E. Mazzucco, D. Zampieri, and E. Marengo, "Iterative optimization of an ESI IT mass spectrometer using regular simplex and a multivariate target function representing the S/N ratio," Journal of the American Society for Mass Spectrometry, vol. 22, no. 1, pp. 118-129, 2011.

[51] E. Marengo, M. Aceto, E. Robotti, M. Oddone, and M. Bobba, "Optimisation of sensitivity in the multi-elemental determination of 83 isotopes by ICP-MS as a function of 21 instrumental operative conditions by modified simplex, principal component analysis and partial least squares," Talanta, vol. 76, no. 5, pp. 1224-1232, 2008.

[52] G. Box, S. Hunter, and W. G. Hunter, Statistics for Experimenters, John Wiley \& Sons, Hoboken, NJ, USA, 2005.

[53] D. L. Massart, B. G. M. Vanderginste, S. M. Deming, Y. Michotte, and L. Kaufman, Chemometrics: A Textbook, Elsevier, Amsterdam, The Netherlands, 1988.

[54] J. Pawliszyn, Solid Phase Microextraction: Theory and Practice, Wiley-VCH, New York, NY, USA, 1997.

[55] A. C. Soria, I. Martínez-Castro, and J. Sanz, "Some aspects of dynamic headspace analysis of volatile components in honey," Food Research International, vol. 41, no. 8, pp. 838-848, 2008.

[56] H. E. Tahir, Z. Xiaobo, H. Xiaowei, S. Jiyong, and A. A. Mariod, "Discrimination of honeys using colorimetric sensor arrays, sensory analysis and gas chromatography techniques," Food Chemistry, vol. 206, pp. 37-43, 2016. 

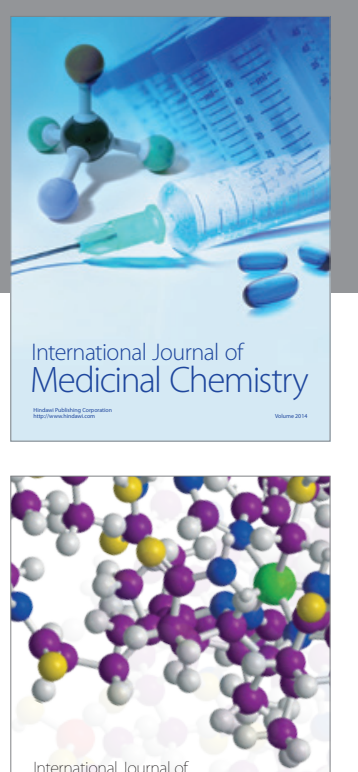

Carbohydrate Chemistry

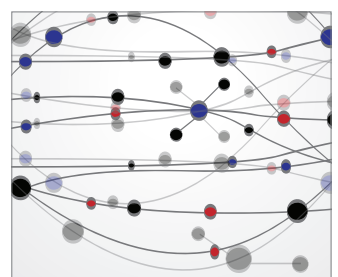

The Scientific World Journal
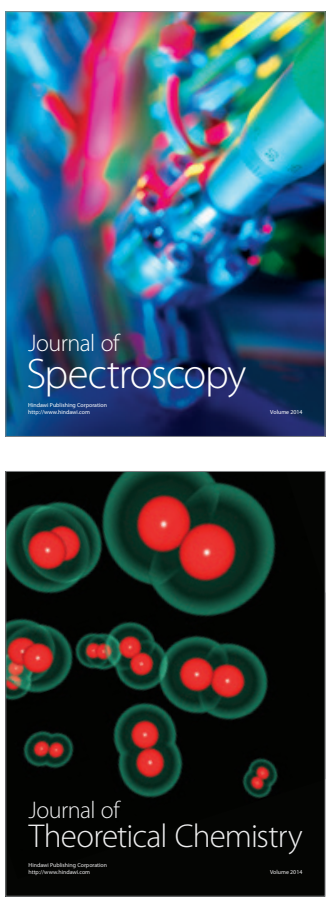
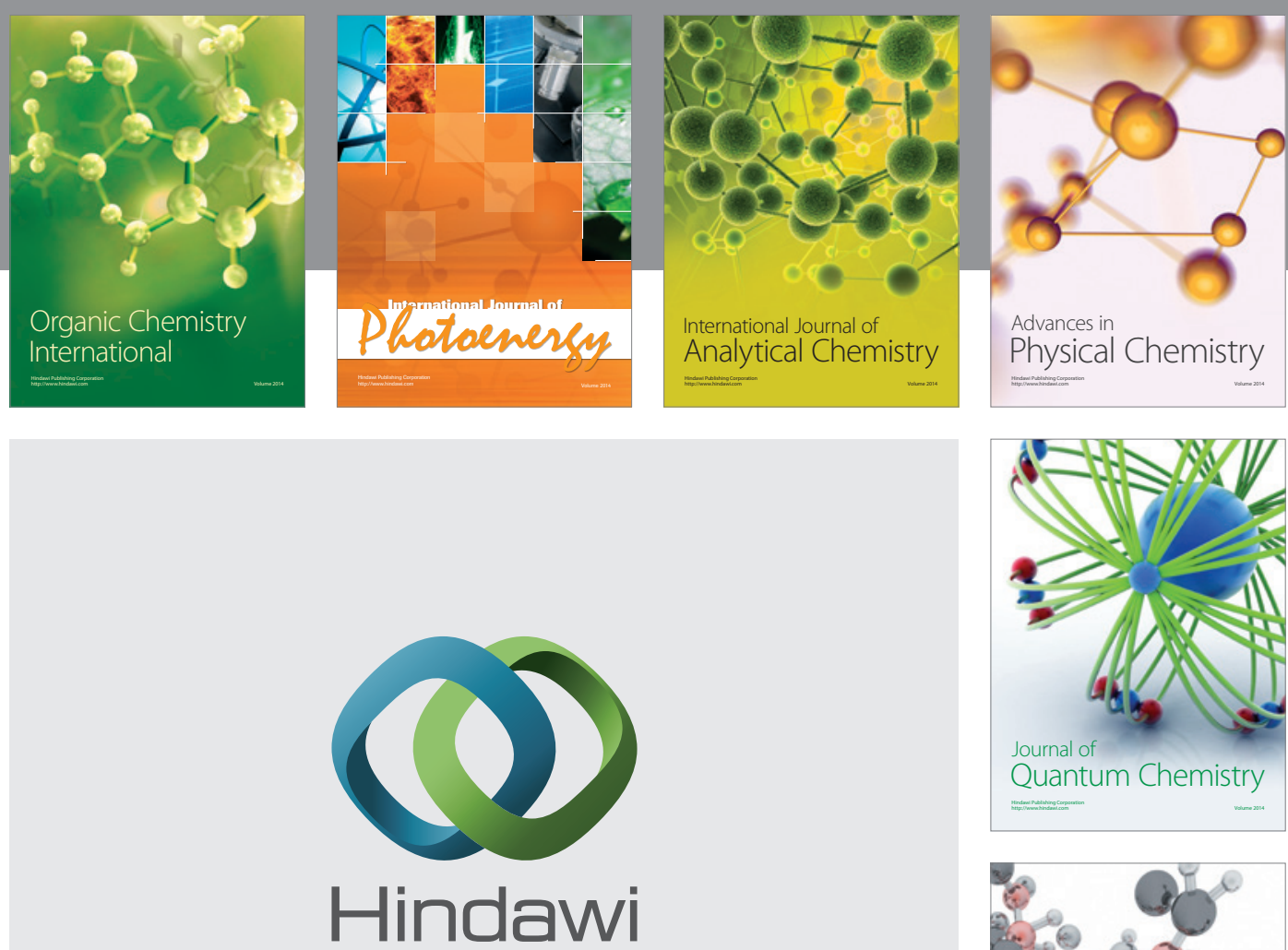

Submit your manuscripts at

https://www.hindawi.com

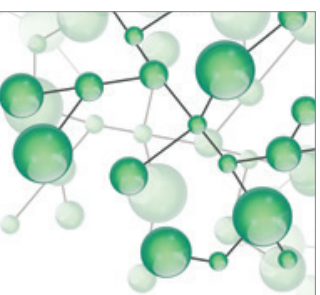

International Journal of

Inorganic Chemistry
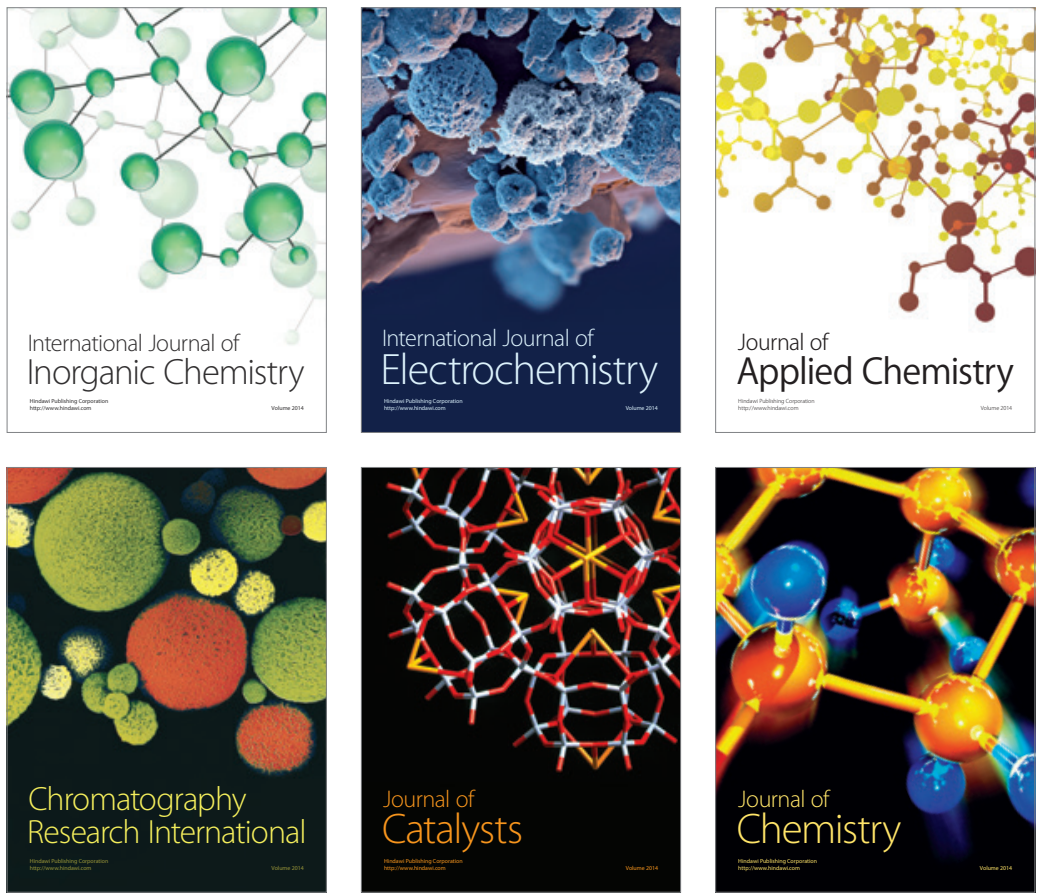

Journal of

Applied Chemistry
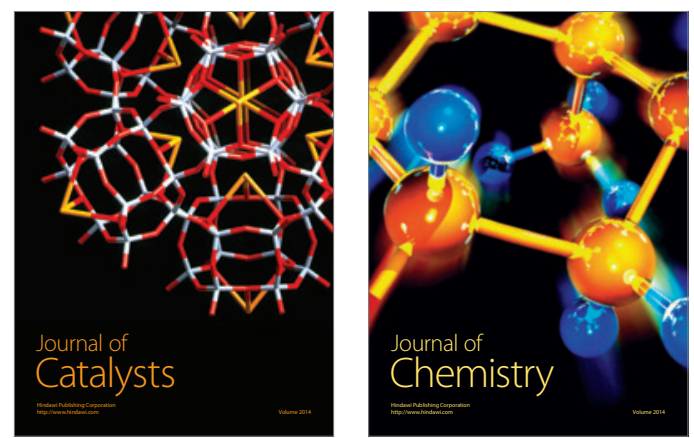
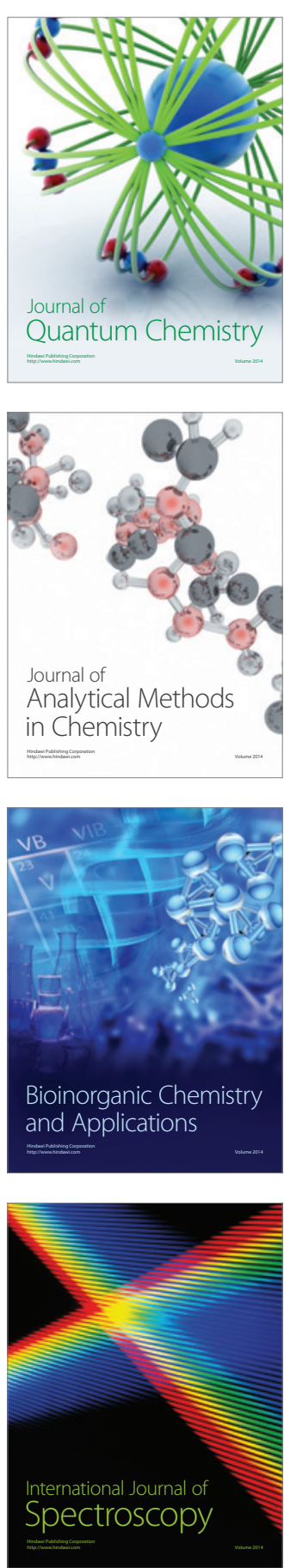